\title{
Estimation of Optical Properties using QAA-V6 model based on MODIS data
}

\author{
Jie Zhan', Dianjun Zhang ${ }^{1}$, Guangyun Zhang', Chenxu Wang', Guoqing Zhou ${ }^{3}$ \\ 1 School of Marine Science and Technology, Tianjin University, Tianjin 300072, China; zhangdianjun123@163.com; \\ 2 School of Geomatics Science and Technology, Nanjing Tech University, Nanjing 211816, China; \\ gyzhang1234@163.com; \\ 3 Guangxi Key Laboratory for Spatial Information and Geomatics, Guilin University of Technology, Guilin, 541004, \\ P. R. China; gzhou@glut.edu.cn
}

KEY WORDS: Ocean Colour Remote Sensing, QAA_V6, Inherent Optical Properties, MODIS Data, Absorption Coefficient

ABSTRACT: Optical property parameters play an important role in ocean colour studies. As a key variable, the absorption coefficient is of great significance for calculating the content of each component in water and simulating the physical, chemical and biological properties of water. The inversion algorithms mainly include empirical model, semi-analytical model and neural network model. In this study, we focused on the QAA_V6, which is the newest version of Quasi-Analytical Algorithm (QAA). It is necessary to test the QAA_V6 model in different conditions. IOCCG data set is used to verify the accuracy of QAA_V6. Additionally, MODIS data of case 1 waters and case 2 waters were selected. After extraction and matching, the data was finally imported into QAA_V6 model to calculate the absorption coefficient with a $\mathrm{R}^{2}$ of 0.999 in both case 1 waters and case 2 waters, thus the QAA_V6 model showed a high accuracy and robust applicability in the inversion of inherent optical properties. Subsequently, it can be further verified for the waters in more complicated areas, providing a firm foundation for implementing QAA into the research of ocean colour remote sensing.

\section{INTRODUCTION}

The research on ocean colour provides a firm foundation for the analysis of the concentration of oceanic components. Geographical distribution information of the oceanic components concentration can be obtained via getting the inherent optical properties represented by the absorption coefficient and the scattering coefficient. The inherent optical properties are difficult to measure through on-site measurements, while the apparent optical properties are relatively easy to obtain by satellite sensors or field measurements. Therefore, the inversion algorithms can be used to estimate the inherent optical properties from the apparent ones.

The QAA algorithm was proposed by Lee et al in 2002 [1], which has been widely used in the field of ocean colour remote sensing. It contains a series of empirical models, semi-analytical models and analytical models. This model was updated to QAA_V5 version in 2009. In 2014, the QAA_V6 version algorithm was developed hereafter. For QAA algorithm, it requires no prior knowledge of water spectrum, which makes it widely used in ocean colour research. The QAA algorithm can obtain the inherent optical properties (IOP) including the absorption coefficient from the apparent optical properties consist of the remote sensing reflectance $(\operatorname{Rrs}(\lambda))$. In this paper, the newest QAA_V6 is used to invert absorption coefficient to verify the accuracy and adaptability of the model [2-13].

\section{METHOD}

The QAA_V6 algorithm was proposed by Lee et al. in 2014[14-19]. It uses the approximate solution of the radiative transfer equation to construct the remote sensing reflectance and the inherent optical properties. The judgment basis that QAA_V6 uses is whether $R_{r s}(670)$ is greater than $0.0015 s r^{-1}$. If $R_{r s}(670)$ is greater than $0.0015 s r^{-1}$, it is suitable for QAA_V6 algorithm, and vice versa QAA_V5 algorithm.

$$
\begin{aligned}
& a\left(\lambda_{0}\right)=a_{w}(670)+0.39\left(\frac{R_{r s}(667)}{R_{r s}(443)+R_{r s}(490)}\right)^{1.14} \\
& b_{b p}\left(\lambda_{0}\right)_{=} b_{b p}(670)_{=} \frac{u\left(\lambda_{0}\right) \times a\left(\lambda_{0}\right)}{1-u\left(\lambda_{0}\right)} b_{b w}(670)
\end{aligned}
$$

Where $a\left(\lambda_{0}\right)$ is the total absorption coefficient at the reference wavelength $\left(\lambda_{0}\right)$, and $b_{b p}\left(\lambda_{0}\right)$ 
refers to the total backscattering coefficient at the wavelength $\left(\lambda_{0}\right)$.

\section{RESULTS}

\subsection{Performance analysis of QAA_V6}

The remote sensing reflectance $R_{r s}$, the absorption coefficient $a_{w}$ of the water body itself, and the scattering coefficient $b_{w}$ of the water body itself is available from IOCCG data set, and the total absorption coefficient $a$ is calculated by QAA_V6. Reading the inherent optical property data that has been calculated in the IOCCG data set is the follow-up work. Then, the inherent optical property data are calculated from the IOCCG data set. Finally, the root mean square error and the average relative error were obtained. The accuracy of the model is analyzed based on the overall performance of the QAA_V6 model.

The inversion results of the absorption coefficients at different wavelength is shown in Figure 1, and the error analysis is shown in Table 1. From analysing the results of linear fitting comparison between IOCCG measured data and model inversion data, we noted that the QAA_V6 model has the best inversion performance when it invert absorption coefficient at 555nm, and the scatter data is evenly concentrated near the 1:1 line. However, at $443 \mathrm{~nm}$, The inversion results are higher than the in situ data, and the model has faults when a(443) is greater than $1 . \mathrm{m}^{-1}$, and the difference between the inversion results and the measured data becomes obvious. The inversion results of the absorption coefficient of the QAA model at $670 \mathrm{~nm}$ wavelength are worse than the other two wavelengths (443nm and 550nm). Most of the values are concentrated between $0.4 \mathrm{~m}^{-1}$ and $0.5 \mathrm{~m}^{-1}$. As shown from the error analysis table, QAA_V6 has the best performance when inverting the a(555), and the MRE and RMSE are $8.22 \%$ and 0.043 respectively. The overall performance is better than the other two wavelengths.

In order to further verify the applicability of the QAA_V6 model, the above-mentioned MODIS is used in this paper, including apparent optical properties, inherent optical properties and remote sensing reflectance, The remote sensing reflectance can be used as the input data, while the inherent optical property, including the absorption coefficient and the backscattering coefficient

etc.

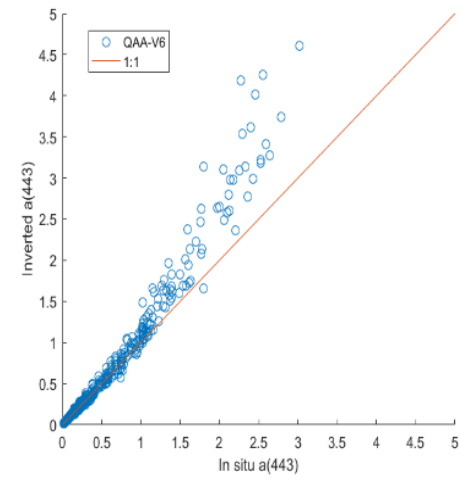

(a)

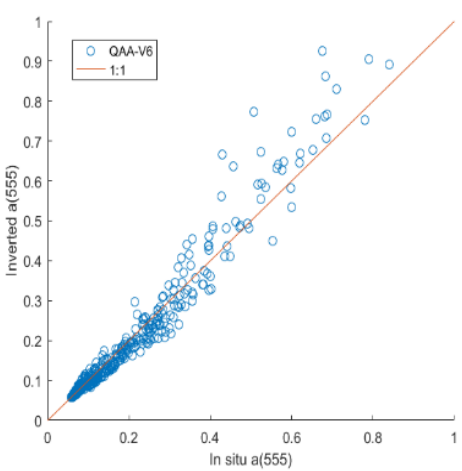

(b)

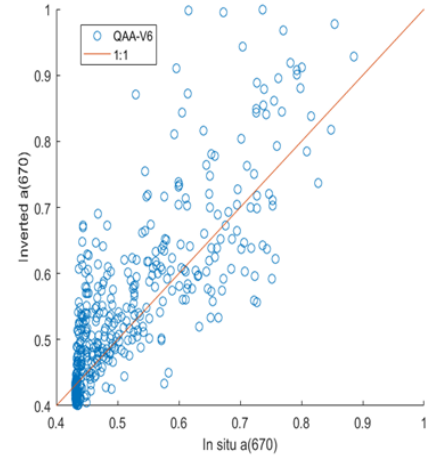

(c)

Figure 1. Performance of using QAA_V6 to invert the absorption coefficient at 443nm(a), 555nm(b) and $670 \mathrm{~nm}(\mathrm{c})$.

Table 1. The error analysis table for QAA_V6 model

\begin{tabular}{rrr}
\hline $\begin{array}{c}\text { Wavelength of } \\
\text { absorption } \\
\text { coefficient }\end{array}$ & $\begin{array}{c}\text { MRE(Average } \\
\text { relative error) }\end{array}$ & $\begin{array}{c}\text { RMSE(Root } \\
\text { mean square error) }\end{array}$ \\
\hline $443 \mathrm{~nm}$ & $9.36 \%$ & 0.3116 \\
$555 \mathrm{~nm}$ & $8.22 \%$ & 0.0439 \\
$670 \mathrm{~nm}$ & $8.99 \%$ & 0.0831 \\
\hline
\end{tabular}




\subsection{Adaptability verification of QAA_V6}

Water bodies can be divided into case 1 water and case 2 water according to different optical properties: the optical properties of case 1 water are mainly determined by phytoplankton and its accompanying organisms while the optical properties of case 2 water are affected by phytoplankton, suspended particulate matter and coloured dissolved organic matter. Oceanic water is case 1 water, and case 2 water is mainly distributed in the near shore and estuary areas. Among them, the data of the Atlantic Ocean in the southern hemisphere is selected as a representative of case 1 water to verify the QAA_V6 model. The Sea of Japan is located at the edge of the western Pacific Ocean and it is typical of coastal water and can be used as a representative of case 2 water.

The verification for the QAA_V6 model in two types of water bodies by $R^{2}$, RMSE and MSE are shown in the following table:

Table 2. QAA_V6 model verification accuracy analysis

\begin{tabular}{ccc}
\hline $\begin{array}{c}\text { Verification } \\
\text { indicator }\end{array}$ & $\begin{array}{c}\text { Atlantic } \\
\text { Ocean } \\
\text { (case } \begin{array}{r}\text { Sea of Japan } \\
\text { water) }\end{array}\end{array}$ \\
(case 2 water) \\
\hline$R^{2}$ & 0.9996 & 0.9994 \\
RMSE & 0.0011 & 0.0014 \\
MSE & $1.84 \%$ & $2.25 \%$ \\
\hline
\end{tabular}

After the analysis of the verification accuracy index in the table 2, QAA_V6 model performs well in inverting the inherent optical properties in case 1 water and case 2 water. The value of $R^{2}$ has reached more than 0.999 , and the value of RMSE is around 0.001, Average relative error is also controlled at a low level, both around $2 \%$. It indicates that the QAA_V6 model can be applied in both cases of water. However, it can be seen from the calculation results that the overall performance of the QAA_V6 model in case 1 water is better than that in the case 2 water, which just proves that the semi-analytic algorithm is more suitable for case 1 water.

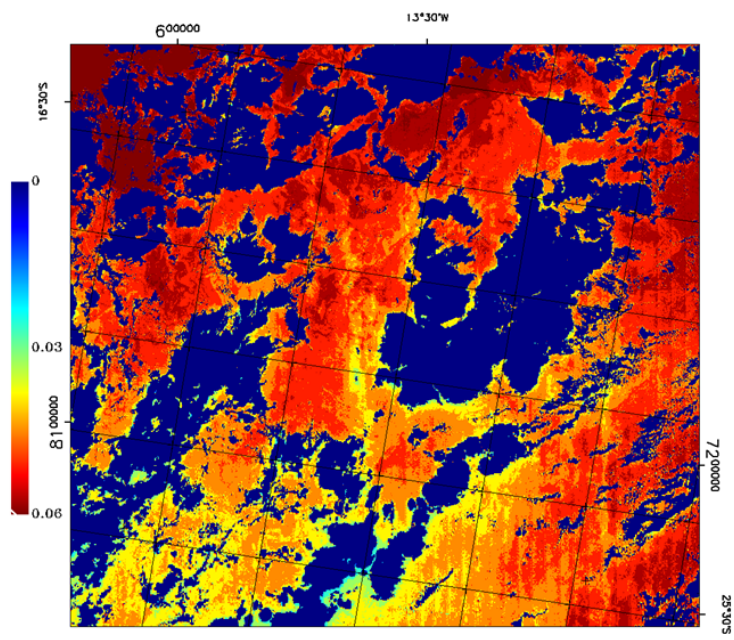

Figure 2. QAA_V6 uses the remote sensing reflectance data to retrieve the absorption coefficient a_555 distribution map of Atlantic Ocean (Southern Hemisphere) on June 15th, 2018

\section{CONCLUSION}

In this paper, QAA_V6 model is used to invert the intrinsic optical properties represented by the absorption coefficient, and the following conclusions are obtained: Using the IOCCG data to compare the accuracy of QAA_V6 inverting absorption coefficient at different wavelength. It can be seen that QAA_V6 model is more suitable for the inversion of absorption coefficient at $555 \mathrm{~nm}$, whose RMSE and MSE are $8.22 \%$ and 0.0439 respectively. Using the product data of MODIS to verify the applicable area of the QAA_V6 model, the QAA_V6 model performs well in inversion of the inherent optical property parameters in case 1 waters and case 2 waters. The value of $R^{2}$ has reached more than 0.999 , and the error is also controlled at a lower level. However, the overall performance of the model in case 1 waters is better than the overall performance in case 2 waters.

\section{ACKNOWLEDGEMENTS}

This paper is financially supported by National Key R\&D Program of China (2018YFC1407400), 2016 Postdoctoral Fund 2016M592886XB and Guangxi Key Laboratory of Spatial Information and Geomatics 15-140-07-15. 


\section{REFERENCES}

1. Lee, Z., et al. "Deriving inherent optical properties from water color: a multiband quasi-analytical algorithm for optically deep waters." Applied Optics. 2002, 41(27): 57555772 .

2. Joshi, I. D. and E. J. D'Sa. "An estuarine-tuned quasi-analytical algorithm (QAA-V): assessment and application to satellite estimates of SPM in Galveston Bay following Hurricane Harvey." Biogeosciences. 2018, 15(13): 4065-4086.

3. Dong, Q., et al. "An algorithm to retrieve absorption coefficient of chromophoric dissolved organic matter from ocean color." Remote sensing of environment. 2013, 128: 259-267.

4. Lee, Z. and K. L. Carder. "Absorption spectrum of phytoplankton pigments derived from hyperspectral remote-sensing reflectance." Remote sensing of environment. 2004, 89(3): 361-368.

5. Lee, Z. "Remote sensing of inherent optical properties: fundamentals, tests of algorithms, and applications." 2006.

6. Zeng, C., et al. "Fluorescence-based approach to estimate the chlorophyll-a concentration of a phytoplankton bloom in ardley cove (Antarctica).7." Remote Sensing. 2017, 9(3): 210.

7. Lee, Z., et al. "Hyperspectral remote sensing for shallow waters: 2. Deriving bottom depths and water properties by optimization." Applied Optics. 1999, 38(18): 3831-3843.

8. Lee, Z., et al. "Euphotic zone depth: Its derivation and implication to ocean-color remote sensing." Journal of Geophysical Research: Oceans. 2007, 112(C3).

9. Lee, Z. P., et al. "Diffuse attenuation coefficient of downwelling irradiance: An evaluation of remote sensing methods." Journal of Geophysical Research: Oceans. 2005, 110(C2).

10. Lee, Z. P., et al. "An inherent-opticalproperty-centered approach to correct the angular effects in water-leaving radiance." Applied Optics. 2011, 50(19): 3155-3167.

11. Lee, Z., et al. "Hyperspectral absorption coefficient of "pure" seawater in the range of
350-550 $\mathrm{nm}$ inverted from remote sensing reflectance." Applied Optics. 2011, 54(3): 546558.

12. Liu, X., et al. "Remote Sensing of Phytoplankton Size Class in Northwest Atlantic from 1998 to 2016: Bio-Optical Algorithms Comparison and Application." Remote Sensing. 2018, 10(7): 1028.

13. Lee, Z., et al. "Penetration of UV-visible solar radiation in the global oceans: Insights from ocean color remote sensing." Journal of Geophysical Research: Oceans. 2013, 118(9): 4241-4255.

14. Lee, Z., et al. "An update of the quasianalytical algorithm (QAA_v5)." International Ocean Color Group Software Report. 2009: 19.

15. Lee, Z., et al. "Update of the Quasi-Analytical Algorithm (QAA_v6) [R/OL]." International Ocean Color Group Software Report [2013-0403]. http://www. ioccg, org/groups/SoftwareOCA/OAA_5. 2014.

16. Gordon, H. R., et al. "A semianalytic radiance model of ocean color." Journal of Geophysical Research: Atmospheres. 1988, 93(D9): 1090910924.

17. Gordon, H. R. and A. Y. Morel. Remote assessment of ocean color for interpretation of satellite visible imagery: a review, Springer Science \& Business Media. 2012.

18. Morel, A. "Optical properties of pure water and pure sea water." Optical aspects of oceanography. 1973, 1(1): 1-24.

19. Morel, A. and L. Prieur. "Analysis of variations in ocean color 1." Limnology and oceanography. 1977, 22(4): 709-722. 